This PDF is a selection from a published volume from the National Bureau of Economic Research

Volume Title: International Financial Issues in the Pacific Rim: Global Imbalances, Financial Liberalization, and Exchange Rate Policy (NBER-EASE Volume 17)

Volume Author/Editor: Takatoshi Ito and Andrew K. Rose, editors

Volume Publisher: The University of Chicago Press

Volume ISBN: 0-226-38682-1

Volume URL: http://www.nber.org/books/ito_08-1

Conference Dates: June 22-24, 2006

Publication Date: July 2008

Chapter Title: Adopting a Common Currency Basket Arrangement into the ASEAN Plus Three

Chapter Author: Eiji Ogawa, Kentaro Kawasaki

Chapter URL: http://www.nber.org/chapters/c6984

Chapter pages in book: (219 - 237) 


\title{
Adopting a Common Currency Basket Arrangement into the ASEAN Plus Three
}

\author{
Eiji Ogawa and Kentaro Kawasaki
}

\subsection{Introduction}

Since the Asian currency crisis, it has been recognized in East Asia that regional monetary and financial cooperation is necessary for preventing and managing future currency crises. The monetary authorities of ASEAN plus three countries (Japan, China, and Korea) established a network of swap arrangements under the Chiang Mai Initiative. They decided to develop the Chiang Mai Initiative at the ASEAN plus three financial ministers' meeting in Istanbul in May of 2005. It is clear that surveillance over the economic situation of the ASEAN plus three countries is necessary for the prevention of currency crises. In fact, monetary authorities have been maintaining surveillance over domestic economic variables such as GDP and inflation rates under the Chiang Mai Initiative.

There still exists a variety of exchange rate regimes in East Asia, although the monetary authorities have been discussing monetary and financial cooperation. For example, Japan and Korea have adopted a freefloating exchange rate system, while China and Malaysia adopted a dollar-peg system prior to mid-2005. Although the monetary authorities of China and Malaysia have announced that they changed their exchange rate regime into a managed floating exchange rate system, they have kept a high weight on the U.S. dollar when conducting exchange rate policy (Ogawa and Sakane 2006; Ito 2005). The variety of exchange rate systems in East Asia shows a possibility of coordination failure in choosing exchange rate regimes (Ogawa and Ito 2002). One of the measures to solve

Eiji Ogawa is a professor at the Graduate School of Commerce and Management at Hitotsubashi University. Kentaro Kawasaki is a professor on the Faculty of Business Administration at Toyo University. 
the coordination failure is for the monetary authorities of the ASEAN plus three countries to adopt a common exchange rate policy. The exchange rate policy coordination of the ASEAN plus three countries should contribute to the stability of intraregional exchange rates between the ASEAN plus three currencies.

It is pointed out that the ASEAN plus three countries should be an Optimum Currency Area (OCA) in order to succeed in adopting a common exchange rate policy. At the same time, some impute difficulties in adopting a common exchange rate policy, because the countries are at different stages of economic development. In this chapter we investigate whether the ASEAN plus three countries are an OCA while we take into account the fact that a currency basket system should be desirable for those economies that have strong economic relationships with more than one specific country. It is noted in the fact that both the Chinese and Malaysian monetary authorities have adopted a currency basket system.

A structural vector autoregression model is used to investigate whether economic shocks, especially aggregate supply shocks, are symmetrical between East Asian countries, given that symmetry of shocks is one of the conditions for OCA. ${ }^{1}$ The symmetry of shocks that are investigated by the structural VAR are no more than a sufficient condition for OCA. A region is regarded as an OCA if one of the other conditions is satisfied while the shocks are asymmetrical among countries. Therefore, asymmetry of shocks should not always show that the relevant region is not an OCA.

A generalized-purchasing power parity (G-PPP) model is used to investigate whether a region is an OCA. The G-PPP is based on a PPP to extend to a multilateral exchange-rate version. In the case of bilateral exchange rates, the PPP holds in the long-run when a bilateral real exchange rate has stationarity, which means that the real exchange rate converges to a level in the long run. If a region has the convergence of the real exchange rates, it is regarded that the region can be an OCA where the nominal exchange rates can stay fixed with each other, although it is not clear which factors among symmetry of shocks, factor mobility, openness of economy, and fiscal transfers make the region an OCA. According to the G-PPP model, multilateral real exchange rates have a cointegration relationship, which means there is a long-run stable relationship between the relevant currencies. The long-run stable relationship among the regional currencies identified by the G-PPP model can be regarded as an OCA in the region.

In addition, the G-PPP model is used to specify a common currency basket as an anchor currency that the monetary authorities are targeting through their exchange rate policies. The common currency basket system can contribute to reducing fluctuations and misalignments of each regional currency against other regional and outside currencies. Fixing each 
regional currency to common outsider currencies means that not only the regional currencies, but also the anchor currencies should form an OCA. It is important to investigate whether regional currencies can form an OCA with outside currencies as an anchor currency.

This paper addresses the following. We explain a theoretical background of the G-PPP model and the relationship between the G-PPP model and the OCA model. Next, we use the G-PPP model to define a common currency area for the ASEAN plus three countries. We explain the adoption of a common currency basket arrangement into the ASEAN plus three countries. In the fourth section, we conduct an empirical analysis of the possibilities of adopting a common currency basket arrangement into the ASEAN plus three countries. In our conclusion we summarize analytical results.

\subsection{OCA Theory and G-PPP Model}

\subsubsection{Real Effective Exchange Rates and Generalized PPP}

Ogawa and Kawasaki (2003), Kawasaki (2005), and Kawasaki and Ogawa (2006) modified the Enders and Hurn's (1994) G-PPP model using a concept of stochastic trends among the real effective exchange rates of countries in the common currency area. We use the extended G-PPP model as well.

The G-PPP model is extended from a simple PPP model by taking into account difficulties in holding PPP, because frequently occurring nominal and real shocks have continuous effects on macrofundamentals. Even in the long run, changes in a bilateral exchange rate depend not only on changes in the relative prices between the related two countries, but also on those in relative prices between the two other countries. Price levels in other countries may effect domestic price levels in the two countries, because prices of intermediate goods imported from abroad may have effects on the prices of domestic products. Therefore it is assumed in the G-PPP model that there are common factors among some bilateral real exchange rates of the home currency vis-à-vis currencies of foreign countries that the home country has strong economic relationships with. Thus, the real exchange rates have a stable equilibrium in the long run if they have strong economic relationships with each other. The G-PPP model explains that a PPP holds if a linear combination of some bilateral real exchange rate series has equilibrium in the long run, even though each of the bilateral rate series is nonstationary. We assume that this linear combination defines the optimum currency area (Mundell 1961).

Suppose that $n$ number of countries are assumed to exist in the world. While country $j$ has $n$ trade partners, it shares strong trade relationships with $m-1$ countries nearby. We also assume that $m$ number of countries, 
which includes country $j$, are expected to form a common currency area because they possess strong economic relationships and share similarities. We could suppose the common currency area as a region where monetary authorities have a common objective to stabilize their trade accounts. Therefore, they conduct a common exchange rate policy and stabilize real effective exchange rates.

Here we define the real effective exchange rates of country $j$ as ree $e_{j}$, which is composed of its all trade partners. While countries $1,2, \ldots, j, \ldots, m$ are expected to adopt a common currency policy, countries $m+1, \ldots, n$ do not share the common currency policy with country $j$. So, $r e e_{j}$ can be denoted with currency of country $j$ :

$$
\begin{aligned}
& r e e_{j}=\xi_{j} \cdot\left(\rho_{j, 1} r e_{j, 1}+\rho_{j, 2} r e_{j, 2}+\ldots+\rho_{j, m} r e_{j, m}\right) \\
& \quad+\left(1-\xi_{j}\right) \cdot\left(\rho_{j, m+1} r e_{j, m+1}+\ldots+\rho_{j, n} r e_{j, n}\right),
\end{aligned}
$$

where $r e_{j, i}$ is the logarithm of the real exchange rate between country $i$ and country $j$. The coefficients: $\rho_{j, i}\left(\sum_{i=1, i \neq j}^{m} \rho_{j, i}=1, \sum_{i=m+1}^{n} \rho_{j, i}=1\right)$ denote that country $j$ 's trade weights on country $i$ and $\xi$ are the trade weights of a group of countries that share the common currency.

Here we add one more assumption that the shocks from the outside of the common currency area do not affect the real effective rate of country $j$ permanently, but temporarily. Because of that, in the case where only country $j$ is permanently affected by the countries that do not adopt the common currency basket as an anchor currency, it is difficult to maintain a common currency in the region.

We focus on the part of real effective exchange rates, which is defined by $m-1$ trade partners who only share the common currency with country $j$ and country $m+1$, or those who do not share the common currency with country $j$. While using the currency of country $m+1$ as a numéraire to define the exchange rate between the regional currencies, equation (1) is rewritten as a currency basket as follows:

$$
c b_{j}=\omega_{j, 1} r e_{j, 1}+\omega_{j, 2} r e_{j, 2}+\ldots+\omega_{j, m} r e_{j, m}+\omega_{j, m+1} r e_{j, m+1},
$$

where the coefficients $\omega_{j, i}\left(\sum_{i=1, i \neq j}^{m+1} \omega_{j, i}=1\right)$ denote country $j$ 's trade weights on country $i$ and country $m+1$.

Furthermore, equation (2) can be rewritten in terms of a currency of country $m+1$ as follows:

$$
\begin{gathered}
c b_{j, t}=\omega_{j, 1}\left(r e_{j, 1, t}-r e_{j, m+1, t}\right)+\ldots+\omega_{j, m-1}\left(r e_{j, m-1, t}-r e_{j, m+1, t}\right)+r e_{j, m+1, t} \\
=\omega_{j, 1} r e_{m+1,1, t}+\ldots+\omega_{j, 1} r e_{m+1, m, t}-r e_{m+1, j, t},
\end{gathered}
$$

where $r e_{j, k}=r e_{j, n}-r e_{k, n}=-r e_{n, j}+r e_{n, k}$.

Since there exists $m$ number of countries that form a currency area, we focus on $m$ number of real effective exchange rates as a currency basket in the region in terms of the currency of country $m+1$ and country $m+1$ 's 
real effective exchange rate defined as a currency basket in the same ways. So, $m+1$ number of real effective exchange rates can be defined as follows:

$$
\begin{gathered}
c b_{1, t}=-r e_{m+1, j, t}+\omega_{1,2} r e_{m+1,2, t}+\ldots+\omega_{1, m} r e_{m+1, m, t} \\
c b_{2, t}=\omega_{2,1} r e_{m+1,1, t}-r e_{m+1,2, t} \ldots+\omega_{2, m} r e_{m+1, m, t} \\
\vdots \\
c b_{m, t}=\omega_{m, 1} r e_{m+1,1, t}+\ldots+\omega_{m, m-1} r e_{m+1, m-1, t}-r e_{m+1, m, t} \\
c b_{m+1, t}=\omega_{m+1,1} r e_{m+1,1, t}+\ldots+\omega_{m+1, m-1} r e_{m+1, m-1, t}+\omega_{m+1, m} r e_{m+1, m, t}
\end{gathered}
$$

These $m+1$ currency baskets can also be shown in a vector form. Matrix $\Omega$ defines the trade weights, and vector re, which includes $m$ elements of the real exchange rate, $r e_{m+1, i}$, the vector form of $m+1$ currency baskets can be written as follows:

$$
\mathbf{c b}_{t}=\Omega \cdot \mathbf{r e}_{t},
$$

where

$$
\underset{(m+1) \times m}{\Omega}=\left[\begin{array}{ccccc}
-1 & \omega_{1,2} & \ldots & \omega_{1, m-1} & \omega_{1, m} \\
\omega_{2,1} & -1 & \ldots & \omega_{2, m-1} & \omega_{2, m} \\
\vdots & \vdots & \ldots & \vdots & \vdots \\
\omega_{m, 1} & \omega_{\mathrm{m}, 2} & \ldots & \omega_{m, m-1} & -1 \\
\omega_{m+1,1} & \omega_{\mathrm{m}+1,2} & \ldots & \omega_{m+1, m-1} & \omega_{m+1, m}
\end{array}\right]
$$

and vector cb includes $m+1$ number of currency baskets.

Each of the currency baskets is expected to include a common stochastic trend because the countries have strong trade relationships with each other and seem to share common technologies. ${ }^{2}$ We assume that $m+1$ number of the currency baskets share a common stochastic trend. Using Stock and Watson's (1988) common trend representation for any cointegration system, we can show that vector $\mathbf{c b}$, which is characterized by $m$ cointegration relationships, can be described as the sum of a stationary component and a nonstationary component.

$$
\mathbf{c b}_{t}=\mathbf{c} \overline{\mathbf{b}}_{t}+\mathbf{c} \tilde{\mathbf{b}}_{t}
$$

The stationary component, $\mathbf{c b}$, is $E\left(\mathbf{c b}_{t}\right)=0$ in this model since the logarithm of the currency baskets can be expected to converge toward the zeromean in the long run. ${ }^{3}$ Therefore, Vector $\mathbf{c b}$ can be only described as the nonstationary component, $\mathbf{c} \tilde{b}$. By the definition of common trend in Stock and Watson (1988), the following equation is obtained:

2. Enders and Hurn (1994) developed the G-PPP model based on the real fundamental macroeconomic variables. They assumed these variables shared common trends within a currency area.

3. We focus on the long-run properties of the OCA; however, macroeconomic policy coordination is needed for a short-term sufficient condition for the OCA. 


$$
\mathbf{c b}_{t}=\Phi \cdot \mathbf{w}_{t},
$$

where $\Phi$ is a $(m+1) \times(m+1)$ matrix. Vector $\mathbf{w}_{t}$ is the nonstationary stochastic trend that is characterized by a random walk. Substituting equation (5) into equation (3), then,

$$
\Phi \cdot \mathbf{w}_{t}=\Omega \cdot \mathbf{r e}_{t} .
$$

Here, the non-null matrix $\Psi$ is composed of $(m+1) \times(m+1)$ and defined to obtain the following equation from equation (6):

$$
\Psi \cdot \Phi \cdot \mathbf{w}_{t}=\Psi \cdot \Omega \cdot \mathbf{r e}_{t}
$$

If there exists a nonzero $\mathbf{w}$ for which $\Psi \cdot \Phi \cdot \mathbf{w}_{t}=0, \Psi \cdot \Phi$ does not have a full rank, the rank condition will be expected as follows:

$$
\operatorname{rank}(\Psi \cdot \Phi)=\operatorname{rank}(\Phi)<m .
$$

As long as the rank condition holds, there exists a non-null matrix $\Psi$ that satisfies the following equation:

$$
\Psi \cdot \Phi=0
$$

When defining $Z=\Psi \cdot \Omega$ and substituting it into equation (7), the following equation is obtained:

$$
Z \cdot \text { re }=0
$$

If we could find a matrix $Z$, which satisfies rank $(Z)<m$ and equation (9), it means that there exists nonzero re for $Z \cdot \mathbf{r e}=0$ and that the matrix $\Psi$ is not a null matrix. Accordingly, the number of rank $\Omega$ must be smaller than $m$. Here, it is assumed that $\operatorname{rank}(Z)=1$. Equation (9) can be shown as the following linear combination:

$$
\zeta_{1} \cdot r e_{m+1,1}+\zeta_{2} \cdot r e_{m+1,2}+\ldots+\zeta_{m} \cdot r e_{m+1, m}=0
$$

where $\zeta_{i}$ is an element of cointegrating vector.

In our extended G-PPP approach, this linear combination defines that $m$ countries form a common currency area in terms of the currency of country $m+1$. It means that this area exhibits optimal currency area in the sense of Mundell (1961). ${ }^{4}$

4. This linear combination is the same formation as that of Enders and Hurn (1994); however, in our extended G-PPP model, country $m+1$ does not belong in the common currency area. As Mundell (1961) pointed out, the idea of the optimum currency area works best if each currency shares internal factor mobility and external factor immobility, but may not exhibit enough internal factor mobility because of trade protections or labor policy between these countries. Domestic policies would be changed and obstacles would be omitted after launching their economic union. Therefore, to investigate the candidates of the future monetary union, we should consider not only the internal mobility but also external common immobility and investigate how external shocks affect each economy in the region. Again, to capture the effect from external economies, the common currency area should be evaluated in terms of macrofundamental variables of external countries. 


\subsection{G-PPP and a Common Currency Basket}

\subsubsection{Adopting the Common Currency Basket Arrangement into the ASEAN Plus Three}

After the Asian currency crisis in 1997, some East Asian countries temporarily changed their exchange rate policy from the de facto dollar peg system to a currency basket system. Each country makes reference to a currency basket that includes not only the three major currencies (the U.S. dollar, the euro, and the yen), but also other East Asian currencies.

In the event that an East Asian country adopts six neighboring countries' currencies and the three major trading partners' currencies into its basket currency as their target policy, country $i$ 's reference rate can be rewritten as follows:

$$
\begin{gathered}
r e_{C B, i}=\varphi_{1, i} \cdot r e_{1, i}+\ldots+\varphi_{7, i} \cdot r e_{7, i}+\varphi_{J P, i} \cdot r e_{J P, i}+\varphi_{E U, i} \cdot \\
r e_{E U, i}+\varphi_{U S, i} \cdot r e_{U S, i}, \\
\sum_{i=1, j \neq i}^{7, J P, E U, U S} \varphi_{j, i}=1
\end{gathered}
$$

Equation (11) can be written in terms of U.S. dollar as follows:

$$
\begin{aligned}
r e_{C B, i} & =\varphi_{1, i} r e_{1, U S}+\varphi_{2, i} r e_{2, U S}+\ldots+\varphi_{m, i} r e_{m, U S} \\
& +\varphi_{J P, i} r e_{J P, U S}+\varphi_{E U, i} r e_{E U, U S}+r e_{U S, i}
\end{aligned}
$$

Here, we suppose that monetary authorities in the seven East Asian countries adopt the currency basket system as their exchange rate policy and refer the same composition of the basket currency. The real exchange rates between each of the East Asian countries and the basket currency can be rewritten as a vector form:

$$
\underset{(7 \times 1)}{\mathbf{r e}_{C B, i}}=\underset{(7 \times 9)}{\mathbf{F}} \cdot \mathbf{r e}_{(i, J P, E U), U S}^{(9 \times 1)},
$$

where $\mathbf{r e}_{C B, i}=\left(r e_{C B, 1}, \ldots, r e_{C B, 7}\right)^{\prime}, \mathbf{r e}_{(i, J P, E U), U S}=\left(r e_{1, U S}, \ldots, r e_{7, U S}, r e_{J P, U S}\right.$, $\left.r e_{E U, U S}\right)^{\prime}$, and

$$
\mathrm{F}=\left(\begin{array}{cccccc}
-1 & \varphi_{1,2} & \ldots & \varphi_{1,7} & \varphi_{1, J P} & \varphi_{1, E U} \\
\varphi_{2,1} & -1 & \ldots & \varphi_{2,7} & \varphi_{2, J P} & \varphi_{2, E U} \\
\vdots & \vdots & \ddots & \vdots & \vdots & \vdots \\
\varphi_{7,1} & \varphi_{7,2} & \ldots & -1 & \varphi_{7, J P} & \varphi_{7, E U}
\end{array}\right) .
$$

By partitioning vector $r e_{(i, J P, E U), U S}$ into two groups - insider currencies and outsider currencies - and both trade weights, and partitioning matrix 
F into the two matrixes for insider and outsider currency, respectively, equation (13) can be rewritten as follows:

$$
\underset{(7 \times 1)}{\mathbf{r e}_{C B, i}}=\underset{(7 \times 7)(7 \times 1)}{\mathbf{F}_{1} \cdot \mathbf{r e}_{1}}+\underset{(7 \times 2)}{\mathbf{F}_{2} \cdot \mathbf{r e}_{2},}
$$

where $\mathbf{F}=\left(\mathbf{F}_{1} \mathbf{F}_{2}\right)$ and $\mathbf{r e}_{(i, J P, E U, U S}=\left(\mathbf{r e}_{1} \mathbf{r e}_{2}\right)^{\prime}$.

Next, if the Japanese yen is included in the region, as well as seven other East Asian countries, the Japanese yen exchange rates against the U.S. dollar should be included in the first part of partitioning vectors, as well as other East Asian exchange rates against the U.S. dollar. Equation (13) should be rewritten as follows:

$$
\underset{(8 \times 1)}{\mathbf{r e}_{C B, i}} \underset{(8 \times 9)}{\mathbf{F}} \cdot \mathbf{r e}_{(i, J P, E U), U S}=\underset{(8 \times 1)}{\mathbf{F}_{1}} \cdot \mathbf{r e}_{1}+\underset{(8 \times 8)}{\mathbf{r e}_{(8 \times 1)}}+\mathbf{F}_{(8 \times 1)} \cdot \mathbf{r e}_{2} .
$$

Equations (13) and (15) could be rewritten in a general form as follows:

$$
\underset{(m \times 1)}{\mathbf{r e}_{C B, i}}=\underset{(m \times m)}{\mathbf{F}_{1}} \cdot \underset{(m \times 1)}{\mathbf{r e}_{1}}+\underset{[m \times(h-m)]]}{\mathbf{F}_{2}} \cdot \underset{[(h-m) \times 1]}{\mathbf{r e}_{2},}
$$

where $h$ is the number of exchange rates that are included in the currency basket and $m$ is the number of countries in the possible region of currency union.

Since matrix $\mathbf{F}_{1}$ has an inverse matrix, vector $\mathbf{r e}_{1}$ is solved by matrix $\mathbf{F}$ as follows:

$$
\mathbf{r e}_{1}=\mathbf{F}_{1}^{-1} \cdot \mathbf{r e}_{C B, i}-\mathbf{F}_{1}^{-1} \mathbf{F}_{2} \cdot \mathbf{r e}_{2}
$$

In equation (17), $\mathbf{r e}_{1}$ is defined by $\mathbf{r e}_{2}$. It means that real exchange rates among East Asian countries in the region would be defined by the currencies outside the region.

If the monetary authorities in the region agree to peg their home currencies to the regional currency basket and intervene in foreign exchange markets to maintain their exchange rate stability, a long-run property of those real exchange rates should be zero: $\mathbf{r e}_{C B, i}=0$. Here, we define the nonnull matrix, $\mathbf{Z}$, which is composed of $m \times m$, equation (16) is written to obtain the following:

$$
\underset{(m \times m)}{\mathbf{Z}} \cdot \underset{(m \times h)}{\mathbf{F}} \cdot \underset{(h \times 1)}{\mathbf{r e}_{h}}=\underset{(m \times m)}{\mathbf{Z}} \cdot \underset{(m \times m)}{\mathbf{F}_{1}} \cdot \underset{(m \times 1)}{\mathbf{r e}_{1}}+\underset{(m \times m)}{\mathbf{Z}} \cdot \underset{[m \times(h-m)]}{\mathbf{F}_{2}} \cdot \underset{[(h-m) \times 1]}{\mathbf{r e}_{2}=0,}
$$

where vector $\mathbf{r e}_{h}$ includes $h$ number of exchange rates between each of all related currencies and the U.S. dollar.

If there exists a nonzero matrix, $\mathbf{Z}$, for which $\mathbf{Z} \cdot \mathbf{r e}_{C B, i}=0, \mathbf{Z}$ does not have a full rank. If we could find a matrix, $\mathbf{Z}$, that satisfies $\operatorname{rank}(\mathbf{Z})<m$, it means that there exists a nonzero $r e$ for $\mathbf{Z} \cdot \mathbf{r e}=0$ and that the matrix $\mathbf{Z}$ is not a null matrix. Accordingly, the number of $\operatorname{rank} \mathbf{Z}$ must be smaller than 
$m$, using the same logic of the rank condition in equation (9). It means that if the exchange rate between the Japanese yen and the U.S. dollar is included in vector $r e_{2}$, the number of $\operatorname{rank} \mathbf{Z}$ for which $\mathbf{Z} \cdot \mathbf{r e}_{C B, i}=0$ would be $h-m=$ 2 ; if it is included in vector re $\mathbf{r}_{1}$, the number of rank would be $h-m=1$. There must be a cointegration relationship among real exchange rates, $r e_{h}$.

\subsection{Empirical Analysis}

\subsubsection{Methodology}

In our earlier works we found several linear combinations that had cointegration relationships when we set the basket weight on three major currencies in advance. In this paper, basket weights on the anchor currencies, the U.S. dollar and the euro, will be set by the estimation. The more countries that adopt the common currency basket exchange rate policy, the less robust result we have with a small sample by using the Johansen approach.

In this paper we use the dynamic OLS (DOLS) to estimate the cointegrating vector. We rewrite equation (10) as follows:

$$
r e_{U S, E U}=\beta_{1} \cdot r e_{U S, 1}+\beta_{2} \cdot r e_{U S, 2}+\ldots+\beta_{m} \cdot r e_{U S, m}+\beta_{J P} \cdot r e_{U S, J P}
$$

Equation (19) represents the long-run relationship, whose coefficients can be estimated by the OLS. ${ }^{5}$ To estimate it, we add the leads and lags, deterministic trend, and constant term into equation (19) as follows:

$$
\begin{gathered}
r e_{U S, E U}=\beta_{0}+\beta_{1} \cdot r e_{U S, 1, t}+\beta_{2} \cdot r e_{U S, 2, t}+\ldots+\beta_{m} \cdot r e_{U S, m, t} \\
+\beta_{J P} \cdot r e_{U S, J P, t}+\sum_{i=1, j=-k}^{m} \sum_{i, j}^{k} \Delta r e_{U S, i, t \neq j}+\beta \cdot t+u_{t}
\end{gathered}
$$

Then, the property of the residuals by the DOLS estimates is shown as follows:

$$
\hat{u}_{t}=\phi_{1} \cdot \hat{u}_{t-1}+\phi_{2} \cdot \hat{u}_{t-2}+\phi_{3} \cdot \hat{u}_{t-3}+\ldots+\phi_{p} \cdot \hat{u}_{t-p}+e_{t},
$$

where the sample distribution will be adjusted as:

$$
\hat{\sigma}_{u}^{\prime}=\frac{\hat{\sigma}_{u}}{1-\phi_{1}-\phi_{2}-\phi_{3}-\ldots-\phi_{p}} .
$$

We attempt to estimate the cointegrating vector with endogenous weights in the common currency basket. In this paper, we test combinations: ASEAN 5, ASEAN 5 plus Korea, ASEAN 5 plus China, and ASEAN 5 plus Korea plus China for $r=2$; and ASEAN 5 plus Japan, ASEAN 5 plus Korea plus Japan, ASEAN 5 plus China plus Japan, and 
ASEAN 5 plus Korea plus China plus Japan for $r=1 .{ }^{6}$ We assumed serial correlation of residuals was captured by an $A R(4)$, and leads and lags was $k=2$ in equation (20).

\subsubsection{Data}

The sample for our empirical tests covers a period between January 1987 and November 2005. Our sample includes data in the period of the Asian currency crisis. We divide the sample periods into a precrisis period from January 1987 to June 1997 and a postcrisis period from January 1999 to November 2005. The eight East Asian countries included are Korea, Singapore, Malaysia, Thailand, the Philippines, Indonesia, China, and Japan. The real exchange rates were based on the monthly data of nominal exchange rates and consumer price indices of the related countries. ${ }^{7}$ We calculated the prior euro to estimate before 1997 crisis. $^{8}$ These data are from the IMF's International Financial Statistics (CD-ROM). ${ }^{9}$

\subsubsection{Analytical Results}

Table 7.1 shows the result of the DOLS for the precrisis period (from January 1987 to June 1997). In the precrisis period, we could not find any combinations where all the coefficients indicated the significant result among the variables for both of rank conditions. While we could find the combinations where three or four countries could conduct a common exchange rate policy with reference to a common currency basket composed of three major currencies, we could not assure the existence of cointegrating vectors in the combinations in our earlier works that included more than five countries. In most cases, the yen was excluded from the possible currency area, as the rank condition was $r=1$. The euro may be excluded from the basket if we look at the cases where the rank condition was $r=2$.

6. As using the OLS approach to estimate the coefficients of variables, the researchers assume that related variables are cointegrated and have only one cointegration relationship. To assure this assumption, we should examine whether the related variables are cointegrated or not before we estimate the coefficients by the dynamic OLS. Here, we have a finite sample to conduct the Johansen's ML approach, and critical values should be adjusted by the method shown in Cheung and Lai (1993), or calculated from Monte Carlo simulation. However, we focus on whether the yen is an insider or outsider, if a currency area exists. Therefore, we assume that there exists at least one cointegration relationship among the countries. Thus, we skip the Johansen test here.

7. For the prior euro real exchange rates, we calculated a GDP-weighted average of CPI.

8. The method of calculation of the prior euro is provided by the PACIFIC Exchange rate service of the University of British Colombia (http://fx.sauder.ubc.ca/).

9. The Chinese consumer price index is provided by Yu Yongding, the Chinese Academy of Social Sciences (CASS). Before the 1994 exchange rate unification, there existed a dual foreign exchange rate market in China. As pointed out in Fernald, Edison, and Loungani (1999), $80 \%$ of transactions related to the Chinese export were referred to the nonofficial, floating exchange rates, therefore, effective nominal depreciation against the U.S. dollar was estimated smaller than $7 \%$, while official rate depreciated $35 \%$ at the 1994 reform. However, the swap date used in their paper was not available to us. We use the official RMB exchange rate in IFS. 


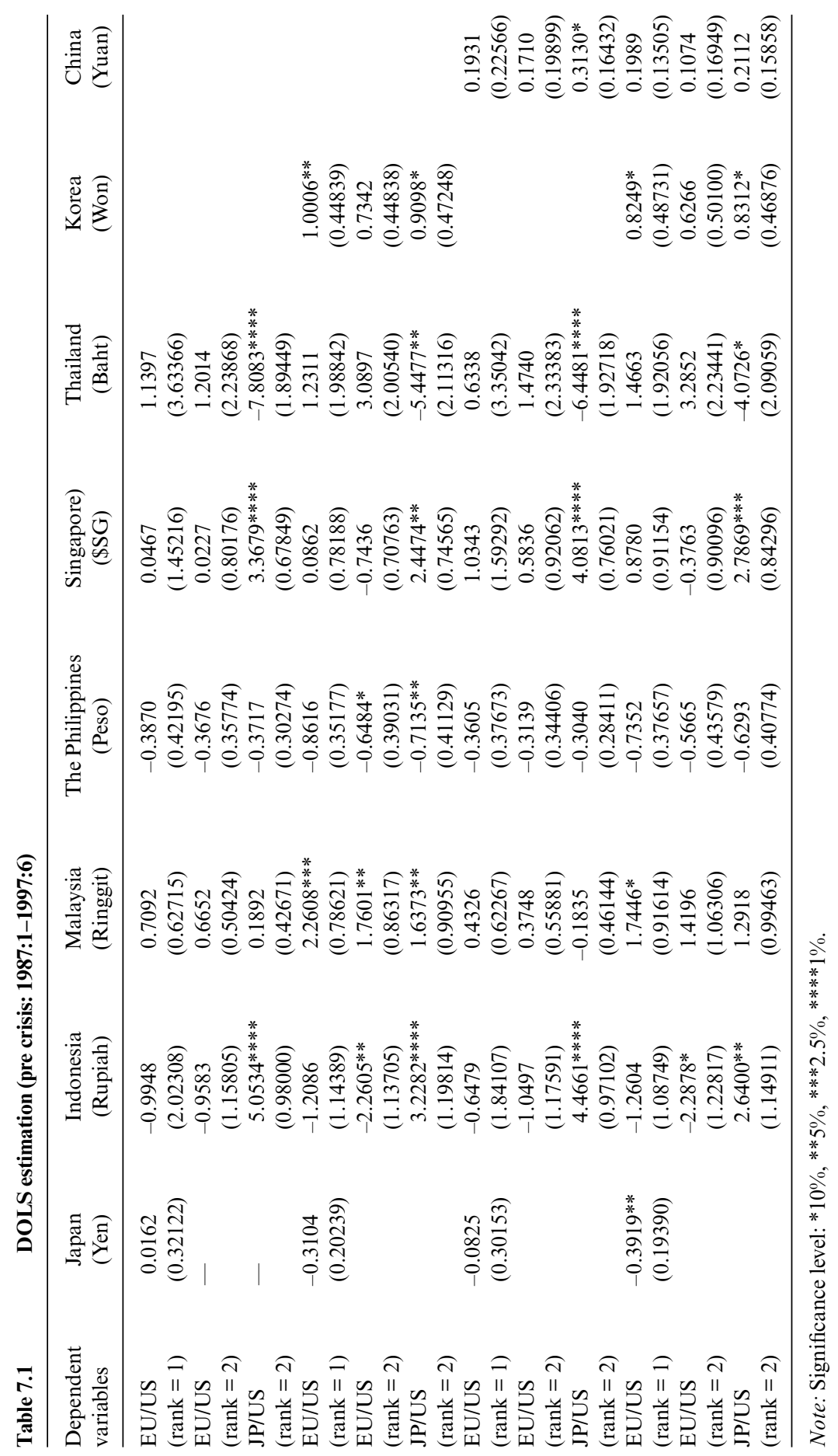


While we could find significant results for the combination, Indonesia, Malaysia, the Philippines, Singapore, Thailand, and Korea, the U.S. dollar and the Japanese yen worked as an outsider currency in the basket, and in addition to other combinations, the euro may be excluded from the currency basket. The de facto dollar peg exchange rate system before the crisis may draw a sharp contrast to much of the fluctuation against the Japanese yen or the euro.

Table 7.2 shows the result of the DOLS for the postcrisis period. All test statistics for the rank condition $r=1$ indicate significance for the combination ASEAN 5 plus Japan, ASEAN 5 plus Korea plus Japan, and ASEAN 5 plus China plus Japan. However, test statistics for $r=2$ indicate insignificance in most cases. This means that the yen should be included in the region as the currency that leads the other East Asian currency stability in the long run. East Asian countries, including Japan, seem to satisfy the conditions of optimum currency area in recent years. While test statistics reported here were dramatically changed from that of the postcrisis period, these results are consistent with the recent developments of integration in the region, because East Asian countries have been deepening the interrelationship in terms of international trade, foreign direct investments, and international finance for $1999-2005 .^{10}$

\subsection{Conclusion}

In this paper we investigate the possibilities of adopting a common currency basket peg arrangement into the ASEAN plus three from a viewpoint of the OCA. A structural VAR model may be used to analyze symmetry of shocks for the OCA, but we point out that the symmetry of shocks is no more than a sufficient condition for the OCA. Instead, we used the DOLS to estimate the cointegrating vector for ASEAN plus three currencies with the currency basket of the U.S. dollar and the euro as the anchor currency according to the modified G-PPP model. In addition, the G-PPP model is useful in specifying a common currency basket as an anchor currency that the monetary authorities are targeting when conducting their exchange rate policies.

We obtained the analytical results that there were only combinations in which three or four countries could conduct a common exchange rate policy with reference to a common currency basket composed of three major currencies in the precrisis period. In the postcrisis period, combinations such as ASEAN 5 plus Japan, ASEAN 5 plus Korea plus Japan, and ASEAN 5 plus China plus Japan are in an area where monetary authorities can conduct a common exchange rate policy with reference to the common

10. Ogawa (2004) found that the linkages of the East Asian currencies with the U.S. dollar have decreased since the Asian currency crisis. 


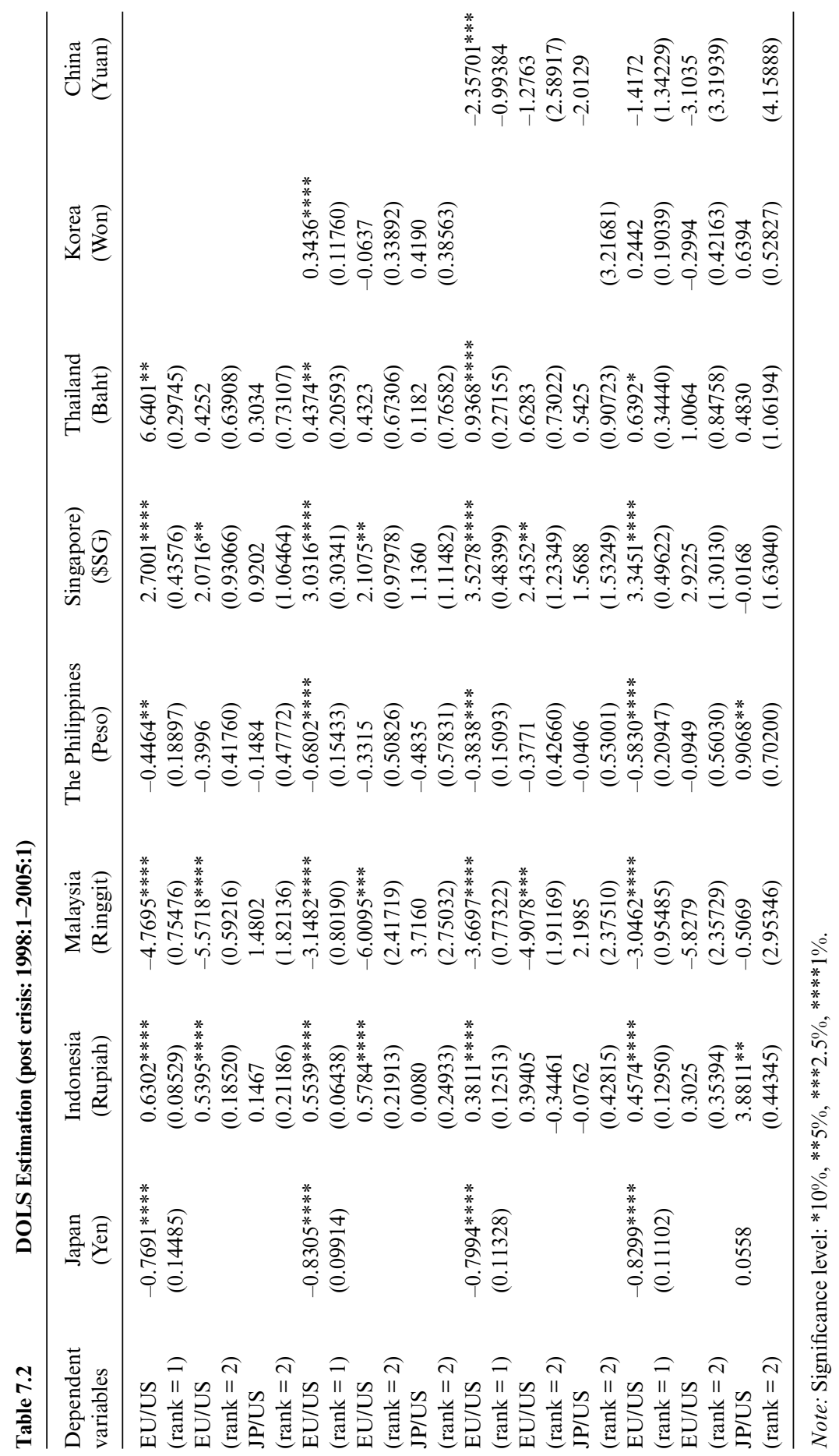


currency basket. Thus, we obtained the analytical results that the yen should be included as an endogenous variable in the long-run relationship, as well as other East Asian currencies, while it worked exogenously as well as the U.S. dollar and the euro in the system composed of the East Asian currencies in the precrisis period. It implies that the possible common currency basket arrangement should be adopted into the region of the ASEAN plus three countries that include Japan.

Thus, the ASEAN plus three countries are forming an OCA in terms of the G-PPP model under the developments of economic integration, such as production networks in East Asia gradually converging economic development stages in recent years. It is more likely for the ASEAN plus three countries to succeed in adopting a common exchange rate policy in the postcrisis period than in the precrisis period.

\section{Appendix}

If the monetary authorities in the region agree to peg their home currencies to the regional currency basket and intervene in foreign exchange markets to maintain their exchange rate stability, the long-run property of their real exchange rates should be $\mathbf{r e}_{C B, i}=0$ in the long-run. It means the non-null matrix $\mathbf{Z}$ should exist for which $\mathbf{Z} \cdot \mathbf{F} \cdot \mathbf{r e}_{(i, J P, E U), U S}=0$ if each of series in vector: $\mathbf{r e}_{(i, J P, E U), U S}$ has unit root.

Here, we assume the exchange rate between the yen and the U.S. Dollar is included in vector $\mathbf{r e}_{1}$, the number of rank condition for the product of non-null matrix $\mathbf{Z}$ and $\mathbf{F}$ would be $h-m=1$, we can define non-null matrix $\mathrm{C}$ as follows:

$$
\begin{aligned}
\underset{(m \times m)(m \times h)}{\mathbf{Z}} \cdot \mathbf{F} & \mathbf{r e}_{(i, J P, E U), U S} \\
(h \times 1) & \underset{(m \times h)}{\mathbf{C}} \cdot \mathbf{r e}_{(i, J P, E U, U S} \\
(h \times 1) & \\
= & \left(\begin{array}{ccccccccc}
\chi_{1,1} & \chi_{1,1} & \chi_{1,3} & \chi_{1,4} & \chi_{1,5} & \chi_{1,6} & \chi_{1,7} & \chi_{1,8} & \chi_{1,9} \\
a \chi_{1,1} & a \chi_{1,2} & a \chi_{1,3} & a \chi_{1,4} & a \chi_{1,5} & a \chi_{1,6} & a \chi_{1,7} & a \chi_{1,8} & a \chi_{1,9} \\
b \chi_{1,1} & b \chi_{1,2} & b \chi_{1,3} & b \chi_{1,4} & b \chi_{1,5} & b \chi_{1,6} & b \chi_{1,7} & b \chi_{1,8} & b \chi_{1,9} \\
c \chi_{1,1} & c \chi_{1,2} & c \chi_{1,3} & c \chi_{1,4} & c \chi_{1,5} & c \chi_{1,6} & c \chi_{1,7} & c \chi_{1,8} & c \chi_{1,9} \\
d \chi_{1,1} & d \chi_{1,2} & d \chi_{1,3} & d \chi_{1,4} & d \chi_{1,5} & d \chi_{1,6} & d \chi_{1,7} & d \chi_{1,8} & d \chi_{1,9} \\
e \chi_{1,1} & e \chi_{1,2} & e \chi_{1,3} & e \chi_{1,4} & e \chi_{1,5} & e \chi_{1,6} & e \chi_{1,7} & e \chi_{1,8} & e \chi_{1,9} \\
f \chi_{1,1} & f \chi_{1,2} & f \chi_{1,3} & f \chi_{1,4} & f \chi_{1,5} & f \chi_{1,6} & f \chi_{1,7} & f \chi_{1,8} & f \chi_{1,9} \\
g \chi_{1,1} & g \chi_{1,2} & g \chi_{1,3} & g \chi_{1,4} & g \chi_{1,5} & g \chi_{1,6} & g \chi_{1,7} & g \chi_{1,8} & g \chi_{1,9}
\end{array}\right)\left(\begin{array}{c}
r e_{1, U S} \\
r e_{2, U S} \\
r e_{3, U S} \\
r e_{4, U S} \\
r e_{5, U S} \\
r e_{6, U S} \\
r e_{7, U S} \\
r e_{J P, U S} \\
r e_{E U, U S}
\end{array}\right)
\end{aligned}
$$


where, $a, b, c, d, e, f$, and $g$ exhibit the weights of the common currency basket composed of insider currencies, which is normalized at country 1 . These can define possible weights of the "regional monetary unit." Therefore:
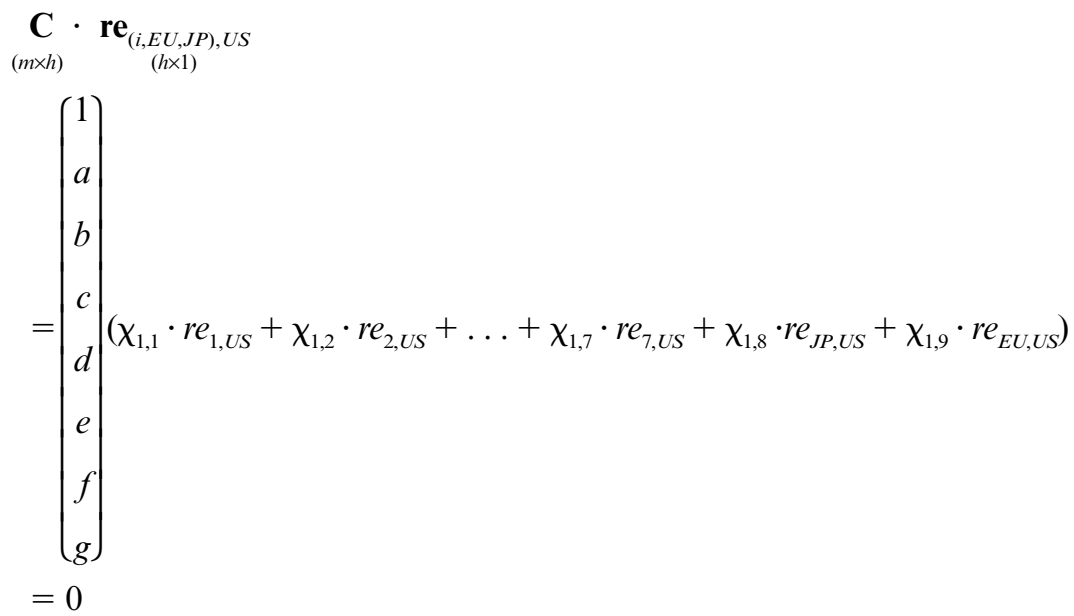

We estimate the coefficients $\chi_{1, i}$ of linear combination above by the dynamic OLS. These would satisfy $\chi_{1, i} \neq 0$ for $a, b, c, d, e, f, g>0$. These are necessary conditions for ensuring that there would be non-null matrix for $\mathrm{re}_{C B, i}=0 .{ }^{11}$

\section{References}

Bayoumi, T., B. Eichengreen, and P. Mauro. 2000. On regional monetary arrangements for ASEAN. CEPR Discussion Paper no. 2411. London: Centre for Economic Policy Research.

Cheung, Y., and K. Lai. 1993. Finite-sample sizes of Johansen's likelihood ratio tests for cointegration. Oxford Bulletin of Economic and Statistics 55 (3): 313-28.

Enders, W., and S. Hurn. 1994. Theory and tests of generalized purchasing-power parity: Common trends and real exchange rates in the Pacific Rim. Review of International Economics 2 (2): 179-90.

Fernald, J., H. Edison, and P. Loungani. 1999. Was China the first domino? Assessing links between China and other Asian economies. Journal of International Money and Finance 18 (4): 515-35.

Frankel, J. A., and S. Wei. 1994. Yen bloc or dollar bloc? Exchange rate policies of the East Asian economies. In Macroeconomic linkage: Savings, exchange rates

11. The magnitudes of the coefficients estimated by DOLS in equation (20) exhibit nothing more than the existence of non-null matrix for $\mathrm{re}_{C B, i}=0$. To analyze welfare effects in integrating these economies, we should estimate $a, b, c, d, e, f, g$, and $h$ by other approaches. 
and capital flows, ed. T. Ito and A. O. Krueger, 295-355. Chicago: University of Chicago Press.

Ito, T. 2005. Chinese RMB Reform. RIETI. Mimeograph.

Ito, T., E. Ogawa, and N. Y. Sasaki. 1998. How did the dollar peg fail in Asia? Journal of the Japanese and International Economies 12:256-304.

Johansen, S., and K. Juselius. 1990. Maximum likelihood estimation and inference on cointegration; with application to the demand for money. Oxford Bulletin of Economics and Statistics 52 (2): 159-210.

Kawai, M., and S. Akiyama. 1998. The role of nominal anchor currencies in exchange arrangements. Journal of the Japanese and International Economies $12: 334-87$.

Kawasaki, K. 2000. A test of OCA in Asian currency area: Empirical analysis based on G-PPP theory (in Japanese). The Hitotsubashi Review 124 (6): 127-46.

Kawasaki, K. 2005. Giving a new life to the PPP theory: The modified generalized PPP model (in Japanese). Keieironshu 66:111-26.

Kawasaki, K., and E. Ogawa. 2006. What should the weights of the three major currencies be in a common currency basket in East Asia? Asian Economic Journal 20 (1): 75-94.

Mundell, R. 1961. A theory of optimum currency areas. Papers and Proceedings of the American Economic Association 51:657-64.

Ogawa, E. 2004. Regional monetary cooperation in East Asia against asymmetric responses to the U.S. dollar depreciation. Journal of Korean Economy 5 (2): 43-72.

Ogawa, E., and T. Ito. 2002. On the desirability of a regional basket currency arrangement. Journal of the Japanese and International Economies 16:317-34.

Ogawa, E., and K. Kawasaki. 2003. Possibility of creating a common currency basket for East Asia. JBICI Discussion Paper no. 5. Tokyo: Japan Bank for International Cooperation.

Ogawa, E., and M. Sakane. 2006. The Chinese yuan after the Chinese exchange rate system reform. China \& World Economy 14 (6): 39-57.

Stock, J., and M. Watson. 1988. Testing for common trends. Journal of the American Statistical Association 83:1097-1107.

\section{Comment Michael P. Dooley}

This chapter addresses an important and difficult issue. For individual Asian countries, managing the nominal exchange rates of a basket of foreign currencies seems a sensible choice. The presumption is that changes in the relative value of major currencies - for example, the dollar, the euro, and the yen, are unlikely to be related to desirable changes in the average real value of the home currency against its trading partners. But we would not assume that any two countries would naturally choose the same basket, or in what amounts to the same thing, would choose to stabilize the value of their currencies within Asia. Clearly, if the Asian countries want greater

Michael P. Dooley is a professor of economics at the University of California, Santa Cruz, and a research associate of the National Bureau of Economic Research. 
stability among themselves they have to at the same time adopt the same policy toward the rest of the world.

The authors attack this problem by looking at the history of bilateral real exchange rates and seeing if relative price movements between inside and outside countries have been temporary or permanent. This is equivalent to testing the feasibility, not the optimality, of a common basket peg. Clearly, if there have been different and persistent relative price changes in the past, we might conclude that such changes are needed to maintain equilibrium in the balance of payments. Adherence to a common basket peg would have to eventually break down. All this assumes that the inside countries are determined to have the same rate of domestic price inflation.

The logic of the euro currency area was that it would float against the rest of the world. A zone of exchange rate stability within Asia would presumably involve managed nominal exchange rates with the rest of the world. In an important sense this is already occurring, informally, since China's apparent heavy weight for the dollar generates relative price changes with other Asian currencies with less weight on the dollar. This limited independence within Asia would have to be eliminated. Either others would have to adopt the weight preferred by China or that weight would have to be modified.

The real problem for such a system will be the mechanism for financing and adjustment within the currency area. Even if relative price changes are not permanent they can last for a long time. Some rules for fiscal adjustment and financing imbalance within the region will have to be established.

\section{Comment Kiyotaka Sato}

The feasibility of forming a regional monetary union and/or establishing a common currency unit in East Asia has gained a great deal of attention and has been lively debated in recent years. Ogawa and Kawasaki attempt to make an important contribution to the literature by introducing a new approach, a Generalized Purchasing Power Parity (G-PPP) model, to analyze whether a common currency basket can be adopted in ASEAN plus three countries.

To investigate a possible regional monetary arrangement, the existing literature typically relies on the theory of optimum currency area (OCA), which proposes several preconditions for forming a currency area. Specifically, recent studies tend to focus on the similarity of the economic structure and/or the symmetry in (real) shocks as a major precondition. The 
Blanchard and Quah (1989) structural vector autoregression (VAR) technique is generally used in these studies to identify the fundamental shocks and to make a correlation analysis of shocks.

In contrast to these studies, Ogawa and Kawasaki employ the G-PPP model, an extended version of a simple PPP model. Indeed, PPP is less likely to hold because the bilateral real exchange rate tends to reflect nominal and real shocks that continuously affect macroeconomic fundamentals of respective countries. However, the G-PPP model assumes that a linear combination of some bilateral real exchange rates may have a stable long-run equilibrium which reflects the commonality in shocks and a strong economic relationship among the countries.

One drawback of the structural VAR approach is that this approach is based on a correlation analysis in identified shocks and, hence, a countryto-country based analysis. In contrast, the G-PPP model relies on a multicountry framework, which is more appropriate than the structural VAR approach to specify a possible group of countries that forms an OCA. Ogawa and Kawasaki attempt to conduct a multivariate cointegration test and to analyze an important question, that is, whether the Japanese yen can be regarded as an insider currency or an outsider currency in the regional currency arrangement. Ogawa and Kawasaki found significant cointegrating vectors in the combination of more than five countries only if including Japan as a member country: ASEAN5 plus Japan, ASEAN5 plus Korea plus Japan, and ASEAN 5 plus China plus Japan. It is concluded that the Japanese yen should be included in the region as they appear to satisfy the OCA conditions.

Ogawa and Kawasaki undoubtedly make an important contribution to the literature on monetary arrangement in East Asia by introducing the G-PPP model. Their conclusion is quite interesting and appears to be reasonable because Japan has increased its presence in East Asia as a major trading partner and a major investment source country for the past few decades. However, there seems to be room for further improvements in their study.

First, the G-PPP model is inherently a long-run model, while the precondition for forming an OCA is more pertinent to the short-term aspect of business cycle synchronization. More specifically, the G-PPP model enables us to find a long-run cointegrating relationship of some bilateral real exchange rate series. Even though real exchange rates are cointegrated, however, the countries in question may face very different patterns of short-term economic fluctuations or disturbances. If the countries encounter such idiosyncratic shocks in the short-run, it may be costly for them to renounce their own monetary policy autonomy and, hence, to establish a common currency. Thus, the authors need to further discuss whether it is enough to consider the long-run aspects of real exchange rate 
comovements as a major precondition for establishing a common currency basket.

Second, Ogawa and Kawasaki use the dynamic OLS (DOLS) method to find a cointegrating relationship for two subperiods: one from January 1987 to June 1997 and the other from January 1999 to November 2005. Whereas the time span is relatively short and the number of observations is small for the cointegration analysis, it is important to focus on the postcrisis monetary arrangement and also to make a comparison between the preand postcrisis periods. However, the DOLS method assumes that there is just one cointegrating relationship, although it is not necessarily correct. It seems better to try the Johansen cointegration test to check the number of cointegrating vectors so that they can support the results of the DOLS estimation, even though the relatively small number of observations may cause less robust results of the Johansen test.

Third, Ogawa and Kawasaki report a very interesting result that Japanese yen should be included in a common currency basket arrangement since they found three combinations that show all coefficients are statistically significant: ASEAN5 plus Japan, ASEAN5 plus Korea plus Japan, ASEAN5 plus China plus Japan. This finding is quite suggestive, but the remaining question is whether there are any criteria to assess which combination is the best for establishing a common currency basket. Another important question is how to interpret the sign and the value of coefficients reported in tables 7.1 and 7.2, which may help us to choose the best combination of countries for establishing a common currency basket arrangement. These aspects will be helpful for further improvement of this study.

\section{References}

Blanchard, O. J., and D. Quah. 1989. The dynamic effects of aggregate demand and supply disturbances. American Economic Review 79:655-673. 